\title{
RP105 plays a cardioprotective role in myocardial ischemia reperfusion injury by regulating the Toll-like receptor $2 / 4$ signaling pathways
}

\author{
WEILING HUANG, JIAN YANG, CHAO HE and JUN YANG \\ Institute of Cardiovascular Diseases, The First College of Clinical Medical Sciences, \\ China Three Gorges University, Yichang, Hubei 443000, P.R. China
}

Received April 25, 2019; Accepted November 20, 2019

DOI: $10.3892 / \mathrm{mmr} .2020 .11242$

\begin{abstract}
The revascularization of blood vessels after myocardial infarction can lead to serious myocardial damage. Previous studies showed that radioprotective $105 \mathrm{kDa}$ protein (RP105) is a specific negative regulator of myocardial ischemia reperfusion injury (MIRI). RP105 can modulate the Toll-like receptor (TLR)2/TLR4 signaling pathways. However, the synergistic effect of TLR2/4 regulated by RP105 during MIRI requires further investigation. To determine this effect, a MIRI model was established in rats in the present study. The expression of RP105 was depleted by transfecting RP105-siRNA and then detected using western blotting. Furthermore, the myocardium tissue was stained with the hematoxylin and eosin staining. Knockdown of RP105 promoted the activity of serum myocardial enzymes during MIRI and increased myocardial infarction. The present results indicated that knockdown of RP105 activated the TLR2/4 signaling pathway by modulating the myeloid differentiation primary response 88 and NF- $\kappa \mathrm{B}$ signaling pathways. Furthermore, decreased expression of RP105 promoted myocardial cell apoptosis, which induced the damage of myocardial ischemic reperfusion. The present results suggested both TLR2 and TLR4 as key targets of RP105, thus RP105 may be a promising candidate to facilitate the development of novel therapeutic strategies for MIRI.
\end{abstract}

\section{Introduction}

Coronary heart disease is caused by structural or functional coronary lesions in the coronary artery, affecting the blood supply and leading to demand imbalances as a result of

Correspondence to: Dr Jun Yang, Institute of Cardiovascular Diseases, The First College of Clinical Medical Sciences, China Three Gorges University, 183 Yiling Road, Yichang, Hubei 443000, P.R. China

E-mail: yangaoli00737@126.com

Key words: radioprotective $105 \mathrm{kDa}$ protein, anti-inflammation, Toll-like receptor 4, Toll-like receptor 2, myocardial ischemia reperfusion injury myocardial damage (1). Acute myocardial infarction (AMI) is a serious disease associated with high mortality rates (2). According to the guidelines of the American College of Cardiology published in 2014, re-establishing the blood supply to ischemic myocardial tissues is the most viable therapeutic approach for the treatment of AMI (3). However, coronary revascularization can induce myocyte damage such as the injury of myocardial structure, cardiac function, myocardial cell metabolism and electrophysiological activity (4). In addition, pathological and physiological changes in endothelial cells, microvascular dysfunction, myocardial necrosis, arrhythmia and myocardial stunning are also associated with coronary revascularization (4). These effects are known as myocardial ischemic reperfusion injury (MIRI) (5). The mechanisms of MIRI have not been fully characterized.

Toll-like receptor 4 (TLR4) is a member of the mammalian TLR family. TLR4 can activate myeloid differentiation factor 88 (MyD88)-dependent pathways (6). TLR4 can also regulate the transcriptional activity of NF- $\mathrm{\kappa B}$ and interferon regulating factor 3 (IRF3), which promotes the production of inflammatory factors (7-9). As a member of TLR family, TLR2 can participate in the inflammatory response by modulating the MyD88 signaling pathway, and the activation of NF- $\mathrm{KB}$ and mitogen activated protein kinase (MAPK) (10). The aim of the present study was to investigate the mechanism of the TLR4/TLR2 signaling pathway in MIRI in order to facilitate the treatment development for MIRI.

Radioprotective $105 \mathrm{kDa}$ protein (RP105) is a single-pass type I membrane protein belonging to the TLR family (11). RP105 plays an important role in regulating the proliferation and radio-activation of murine $\mathrm{B}$ cells (12). The expression level of RP105 is closely associated with the inflammatory response in MIRI (13). RP105 acts as a key inhibitor of the TLR4 pathway by forming the RP105/myeloid differentiation protein-1 complex (MD-1) and decreases the binding of TLR4 to ligands $(14,15)$. MD-2 is a glycoprotein that was discovered by sequence homology with MD-1. MD-2 determines the surface expression and signal transmission of TLR4 $(11,16)$. Transfection of RP105 into cardiocytes significantly decreased the production of pro-inflammatory cytokines to alleviate the heart from MIRI by inhibiting both the TLR4/MyD88 and TLR4/TIR-domain-containing adapter-inducing interferon- $\beta$ (TRIF) signaling pathways $(17,18)$. 
The TLR2-dependent p38/MAPK and transcription factor activator protein-1 (AP-1) signaling pathways play critical roles in the pathogenesis of reperfusion injury of the myocardium, retina, liver and intestine (19-21). In the present study, the role of RP105 and the mechanism via which RP105 regulated TLR2/4 in MIRI were investigated by knockdown of RP105 in the cardiomyocytes of rats. The present results indicated the role of the RP105/TLR2/4 axis in MIRI.

\section{Materials and methods}

Animals. In total, 75 adult Sprague-Dawley rats (males; weight, 220-250 g; age, 7-8 weeks) were provided by the Animal Experiment Center of China Three Gorges University (certificate no. SYXK2017-0061). The animal experiments were approved by the Animal Care and Use Department of China Three Gorges University. All rats were housed in a controlled temperature $\left(25 \pm 2^{\circ} \mathrm{C}\right)$ with relative humidity $60 \pm 5 \%$ and 12:12-h light/dark cycle. All rats were housed in a specific pathogen-free barrier environment with free access to food and water.

The rats were randomly divided into the following five groups ( $n=15 /$ group): i) Sham operation group (sham group); ii) saline injection and ischemic and reperfusion (I/R) operation group (I/R); iii) myocardial I/R with Ad-RP105 group (Ad-RP105); iv) myocardial I/R with Ad-RP105-small interfering RNA (siRNA) group (Ad-RP105-siRNA); and v) myocardial I/R with Ad-enhanced green fluorescence protein (EGFP)-siRNA group (Ad-G-siRNA).

Construction of adenoviral vectors. The adenovirus vectors expressing EGFP-RP105- siRNA (5'-UAAUAGCUC UGGCAAUUUGGC-3'; Shanghai GeneChem Co., Ltd.), EGFP-RP105 (full-length cDNA of RP-105) or EGFP-siRNA (5'-TAG TCG CAT ACG GAACAT TCG-3'; Shanghai GeneChem Co., Ltd.) were constructed by inserting the sequence into the PL-SIN lentiviral vector (Plasmid \#21316; Addgene, USA). Then, $5 \mu \mathrm{g}$ of plasmids were transfected into 293 cells to amplify the adenovirus. The adenoviruses were further purified with the Adeno-X TM Virus Purification kit (BD Biosciences Clontech) after transfection for $48 \mathrm{~h}$ at romm temperature according to the manufacturer's instructions.

MIRI model. The establishment of the MIRI model was performed as previously described (22). Animals were anesthetized by intraperitoneally injecting $40 \mathrm{mg} / \mathrm{kg}$ sodium pentobarbital. The subcutaneous tissue was cut and separated along the upper part of the breastbone. The trachea was fully exposed for insertion; a venous indwelling $24 \mathrm{G}$ needle was used to ventilate the animal via endotracheal intubation. The animal ventilator was set at the rate of 80 breaths/min and the inspiratory/expiratory ratio was set as $2: 1$. The chest was exposed by a left thoracotomy between the fourth and fifth ribs. In total, $100 \mu 1$ of saline, $30 \mu 1$ of lentivirus expressing Ad-RP105-EGFP, Ad-G-siRNA or Ad-RP105-siRNA was injected at the apex of four separate positions in the heart of each group. After 3 days, the rats were again subjected to anesthesia, ventilation and thoracotomy as described above. The heart was exposed once again, and the left anterior descending coronary artery (LAD) was ligated using 6-0 silk suture with medical latex tubing to ensure full occlusion of LAD. Myocardial ischemia was recorded by serum detection. All animals were underwent $30 \mathrm{~min}$ of myocardial ischemia followed by $3 \mathrm{~h}$ of reperfusion as described previously (23-25). Rats in the sham group were subjected to the same operation but without blockage of LAD. After I/R surgery, $200 \mu 1$ of blood was collected from the inferior vena cava of the rats. The euthanasia of rats was performed via cervical dislocation after anesthesia. Humane endpoints set for the euthanasia of rats at the end of the experiment included behavioral changes such as labored breathing, not eating or drinking, half-closed eyes and reduced exploration. The death of the animals was verified by checking the breathing rate, heartbeat and pupillary reflexes. The health and behaviors of rats were monitored every day during the experiments. Myocardial tissues were collected for subsequent experiments.

Immunofluorescence assay. After I/R for $3 \mathrm{~h}$, myocardium was immediately fixed with $4 \%$ paraformaldehyde at room temperature for $2 \mathrm{~h}$, embedded in paraffin and sliced $(4 \mu \mathrm{m})$. Slices were dewaxed and then underwent antigen fixing. Slices were blocked with 1\% BSA (Sigma-Aldrich; Merck $\mathrm{KGaA}$ ) for $30 \mathrm{~min}$ at room temperature (RT) and incubated with anti-RP105 antibody (cat. no. Sc-13592; 1:1,000; Santa Cruz Biotechnology, Inc.) overnight at $4^{\circ} \mathrm{C}$. Then, the slices were incubated with goat anti-Rat $\operatorname{IgG}(\mathrm{H}+\mathrm{L})$ cross-adsorbed secondary antibody (1:5,000; cat. no. A-11006; Thermo Fisher Scientific, Inc.) for $60 \mathrm{~min}$ at RT and subsequently stained with DAPI at room temperature for $10 \mathrm{~min}$ in the dark. The signal was measured using a fluorescence microscope (magnification, x100; cat. no. BX51; Olympus Corporation).

Western blotting. Cardiac tissues were lysed using RIPA lysis buffer (Beyotime Institute of Biotechnology). The protein concentration was determined using a bicinchoninic acid protein assay kit (Beyotime Institute of Biotechnology). Then, 20 ug of protein was separated via $12 \%$ SDS-PAGE and transferred onto nitrocellulose membranes. The membranes were first blocked with $5 \%$ non-fat milk for $1 \mathrm{~h}$ at RT, and then incubated with specific primary antibodies overnight at $4^{\circ} \mathrm{C}$, including anti-TLR4 (1:1,000; cat. no. ab13556; Abcam), anti-TLR2 (1:2,000; cat. no. sc-10739; Santa Cruz Biotechnology, Inc.), anti-RP105 (1:1,000; cat. no. Sc-13592; Santa Cruz Biotechnology, Inc.), anti-Bcl-2 (1:1,000; cat. no. ab196495; Abcam), anti-cleaved caspase-3 (1:1,000; cat. no. ab2302; Abcam), anti-MYD88 (1:1,000; cat. no. ab2064; Abcam) and anti-NF- $\kappa B$ antibody (1:1,000; cat. no. Ab32536; Abcam). Membranes were then incubated with horseradish peroxidase-conjugated secondary antibodies (1:5,000; cat. nos. Ab97046 and Ab97057; Abcam) at RT for $1 \mathrm{~h}$. The bands were exposed with Pierce ECL western blotting substrate (cat. no. 32106; Thermo Fisher Scientific, Inc). The expression of GAPDH (1:3,000; cat. no. Ab181602; Abcam) was detected to normalize the signals. The expression of proteins was qualified using ImageJ software (1.47; National Institutes of Health)

Evaluation of myocardial infarct size. The myocardial infarct area was measured with the triphenyltrazolium chloride (TTC) staining. After being frozen at $-80^{\circ} \mathrm{C}$ for $5 \mathrm{~min}$, the hearts were sliced into five sections (thickness, $2 \mathrm{~mm}$ ) and incubated with 
$1.5 \% \mathrm{TTC}$ at $37^{\circ} \mathrm{C}$ for $15 \mathrm{~min}$. Normal myocardial tissues stained red and the infarction region stained white with TTC. The myocardial infarct size was calculated using Image-Pro Plus 5.0 software (Media Cybernetics, Inc.).

Hematoxylin and eosin (H\&E) staining. Samples of cardiac tissue were fixed for $24 \mathrm{~h}$ at RT with $4 \%$ buffered formalin, embedded in paraffin and then cut into slices (thickness, $5 \mathrm{~mm}$ ). Afterwards, the heart tissues were stained with H\&E for $5 \mathrm{~min}$ at room temperature and imaged with a light microscope (magnification, $\mathrm{x} 200$ ).

Indexes of blood. The blood of rats treated with $1 \mathrm{ml} \mathrm{10 \%}$ $\mathrm{KCl}$ was collected and centrifuged at $1,500 \mathrm{x}$ for $10 \mathrm{~min}$ at $4^{\circ} \mathrm{C}$. The serum was obtained and the levels of creatine kinase (CK), MB isoenzyme of CK (CK-MB), and lactate dehydrogenase $(\mathrm{LDH})$ was determined with lactate dehydrogenase kit (cat. no. 2400837; Beijing Kemeidongya Biotechnology Co., Ltd.) according to the manufacturer's protocols.

Reverse transcription-quantitative PCR (RT-qPCR). Total RNA was extracted from the myocardial samples using TRIzol ${ }^{\circledR}$ reagent (Invitrogen; Thermo Fisher Scientific, Inc.). RNA was reverse transcribed into cDNA using the High-Capacity RNA-to cDNA kit (cat. no. 4387406; Thermo Fisher Scientific, Inc.). RT-qPCR was conducted with an SYBR Green Master Mix kit (Thermo Fisher Scientific, Inc.) on an ABI Prism 7500 system (Applied Biosystems; Thermo Fisher Scientific, Inc.). The PCR conditions were set as follows: $2 \mathrm{~min}$ at $50^{\circ} \mathrm{C}, 95^{\circ} \mathrm{C}$ for $10 \mathrm{~min}$, then 40 cycles of $95^{\circ} \mathrm{C}$ for $30 \mathrm{sec}$ and $60^{\circ} \mathrm{C}$ for $30 \mathrm{sec}$. The expression of RP105 was normalized to that of GAPDH using the $2^{-\Delta \Delta C q}$ method (26). The primers used were as follows: RP105, forward 5'-GAGCCTGAACCTGAG CTACA-3', reverse 5'-GGAGGCAGTGGGAGAGATTT-3'; GAPDH, forward 5'-ACAGCAACAGGGTGGTGGAC-3', reverse 5'-TTTGAGGGTGCAGCGAACTT-3'.

Co-immunoprecipitation. Tissues were added into homogenizing microtubes (OMNI International, Inc.) containing $1 \mathrm{ml}$ home-made NP-40 lysis buffer [In 11 of NP-40 lysis buffer: $30 \mathrm{ml}$ of $5 \mathrm{M} \mathrm{NaCl}, 100 \mathrm{ml}$ of $10 \% \mathrm{NP}-40,50 \mathrm{ml}$ of $1 \mathrm{M}$ Tris (pH 8.0) and $820 \mathrm{ml}$ of $\mathrm{H}_{2} \mathrm{O}$. Stored at $4^{\circ} \mathrm{C}$ ] and immediately homogenized using the Precellys ${ }^{\circledR} 24$ Homogenizer (Bertin Instruments) at $4,000 \mathrm{xg}$ for $1 \mathrm{~min}$ at $4^{\circ} \mathrm{C}$. The homogenized mix was centrifuged at $10,000 \mathrm{x}$ g for $15 \mathrm{~min}$ at $4^{\circ} \mathrm{C}$ and the clarified supernatant was collected. The supernatant was pre-cleared by incubating with protein A beads for $1 \mathrm{~h}$ at $4^{\circ} \mathrm{C}$. Afterwards, lysate was incubated with anti-MD2 antibody ( $2 \mu \mathrm{g}$; cat. no. sc-80183; Santa Cruz Biotechnology, Inc.) at $4^{\circ} \mathrm{C}$ overnight. IgG antibody (1:200; cat. no. sc-2025; Santa Cruz Biotechnology, Inc.) was used as the negative control. Then, Protein A agarose beads was added and incubated for $4 \mathrm{~h}$ at $4^{\circ} \mathrm{C}$, followed by washing twice with PBS on ice. The binding between MD2 and TLR2/TLR4 was detected by western blotting with anti-MD-2 and anti-TLR2/4 antibodies (anti-TLR4: 1:1,000; cat. no. ab13556; Abcam; and anti-TLR2; 1:2,000; cat. no. sc-10739; Santa Cruz Biotechnology, Inc.).

Statistical analysis. Data are presented as mean \pm SD. Statistical significance was analyzed using one-way ANOVA followed by Tukey's test. $\mathrm{P}<0.05$ was considered to indicate a statistically significant difference.

\section{Results}

Overexpression or knockdown of RP105 in rat cardiac muscle tissue. To explore the anti-inflammatory and cardioprotective roles of RP105 in MIRI, the adenoviral vectors expressing Ad-RP105-siRNA or Ad-EGFP-RP105 were injected into four individual sites at the apex of each rat heart. The transfection efficiency was identified by detecting the expression level of EGFP in the Ad-EGFP-RP105 and Ad-EGFP-RP105-siRNA groups (Fig. 1A). Compared with the Ad-G-siRNA group, both the mRNA and protein expression levels of RP105 in the Ad-RP105-siRNA group were significantly decreased (Fig. 1B and C). Transfection with Ad-EGFP-RP105 significantly increased the expression levels of RP105 in the myocardial tissue compared with the I/R group.

Knockdown of RP105 promotes the activity of serum myocardial enzymes during MIRI. The concentrations of serum myocardial enzymes CK-MB, LDH and CK were increased after ischemia for $30 \mathrm{~min}$ followed by reperfusion for $3 \mathrm{~h}$ (I/R group vs. sham group; Fig. 2A-C). Additionally, knockdown of RP105 significantly increased the concentration of CK-MB, LDH and CK in myocardium compared with the Ad-G-siRNA group (Fig. 2A-C). In contrast, overexpression of RP105 significantly decreased the levels of CK-MB, $\mathrm{LDH}$ and $\mathrm{CK}$ in the rat myocardium (Ad-R vs. I/R group; Fig. 2A-C). The present results suggested that knockdown of RP105 enhanced the activity of myocardial enzymes during MIRI in rats.

Silencing of RP105 increases myocardial infarction during MIRI. To investigate whether the knockdown of RP105 aggravated myocardial damage during MIRI, the myocardial infarction of each rat was evaluated by TTC staining. The myocardial infarction area was significantly increased in the RP105 knockdown group compared with the Ad-G-siRNA group (Fig. 3A and B). The present results indicated that overexpression of RP105 suppressed myocardial infarction in rats. Histopathological alterations in ischemic myocardia followed by reperfusion were identified via H\&E staining (Fig. 3C). Only a few myocardial infarcts were identified in the control group (Fig. 3A and B). However, obvious myocardial degeneration and necrosis, myocardial fibers disorder, interstitial edema and infiltration of inflammatory cells were identified in the other experimental groups. Notably, these phenotypes were more significant in RP105 knockdown group compared with Ad-G-siRNA group (Fig. 3A and B). Mild myocardial fiber disorder and swelling were observed in RP105 overexpression group (Fig. 3C). The present results indicated the protective role of RP105 against myocardial infarction during MIRI.

Knockdown of RP105 increases the expression levels of TLR2 and TLR4 in MIRI. To investigate the involvement of the TLR2/4 signaling pathway in MIRI, myocardial tissues of rats were collected after myocardial ischemia for $30 \mathrm{~min}$ and reperfusion for $3 \mathrm{~h}$. The expression levels of TLR 2 and TLR4 in rat myocardium were detected via western blotting. The present 
A

Ad-RP105-siRNA

Ad-RP105
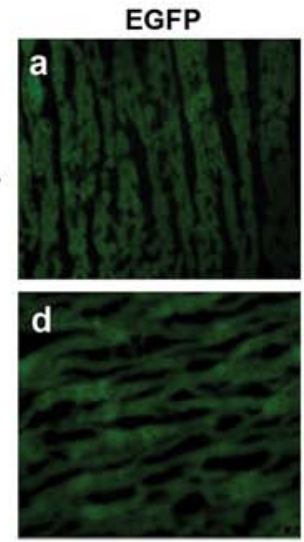

DAPI
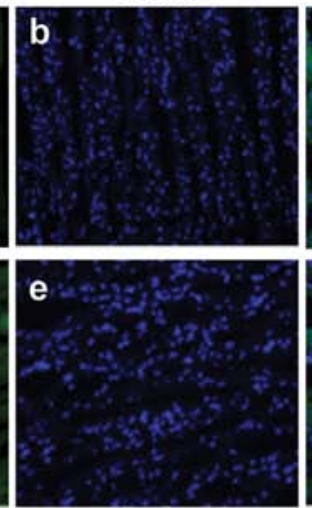

Merged
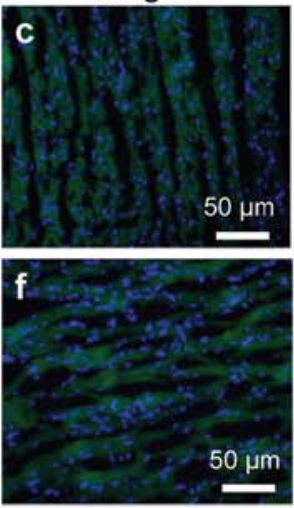

B

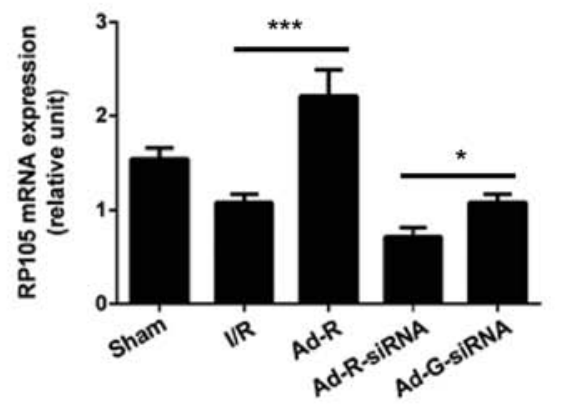

C

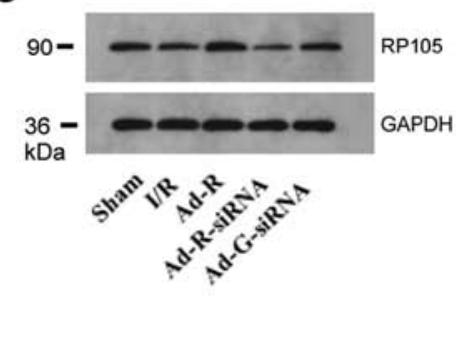

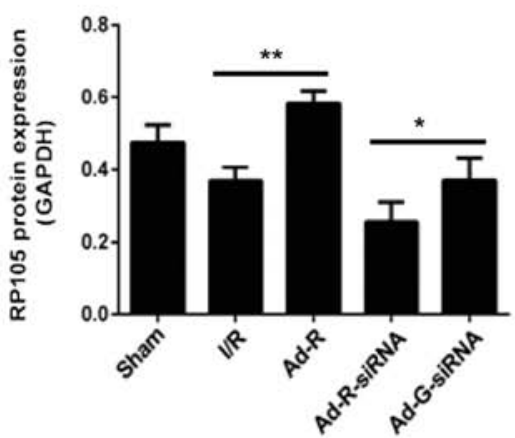

Figure 1. Overexpression or knockdown of RP105 in rat cardiac muscle tissue. (A) Expression levels of EGFP, with the indicated adenovirus gene injection for RP105 overexpression and RP105-siRNA, and DAPI-labeled nuclei density of cardiomyocytes. Scale bar, $50 \mu \mathrm{m}$. (B) mRNA expression of RP105 in rat cardiac muscle tissues was detected by reverse transcription-quantitative PCR after transfection with the indicated vector. (C) Protein expression levels of RP105 in rat cardiac muscle tissue. $\mathrm{P}<0.05,{ }^{* *} \mathrm{P}<0.01,{ }^{* * *} \mathrm{P}<0.001$. Ad, adenovirus; RP105, radioprotective 105 kDa protein; siRNA, small interfering RNA; EGFP, enhanced green fluorescent protein; sham, control sham group; I/R, ischemic and reperfusion; Ad-R, Ad-RP105 group; Ad-R-siRNA, Ad-RP105-siRNA group; Ad-G-siRNA, Ad-EGFP-siRNA group.
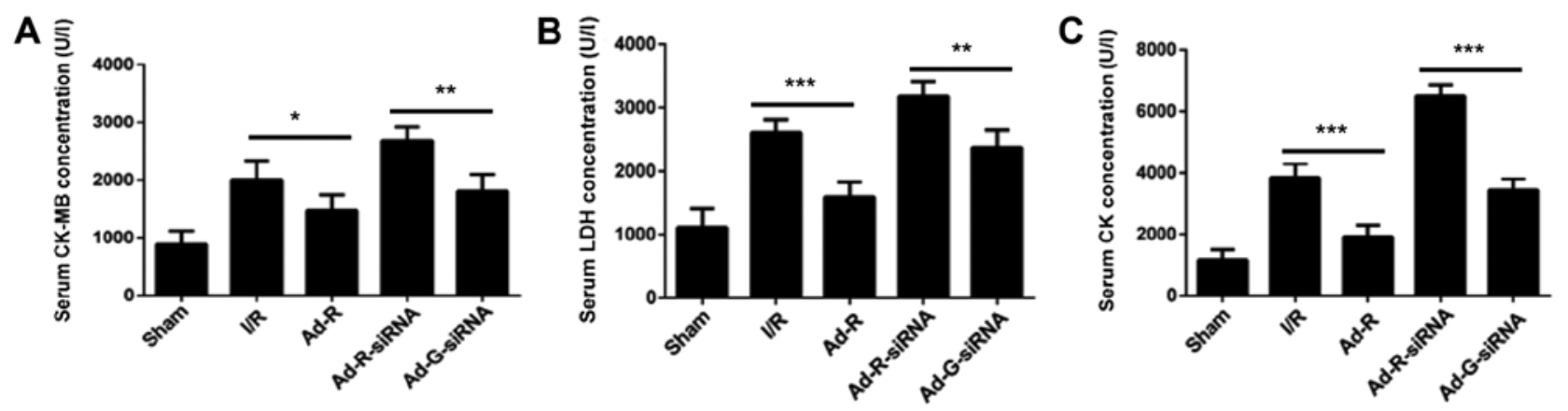

Figure 2. Knockdown of RP105 promotes the activity of serum myocardial enzymes during MIRI. Levels of serum (A) CK-MB, (B) LDH and (C) CK in sham, I/R, Ad-R, Ad-R-siRNA and Ad-G-siRNA groups. ${ }^{*} \mathrm{P}<0.05,{ }^{* *} \mathrm{P}<0.01,{ }^{* * *} \mathrm{P}<0.001$. Ad, adenovirus; RP105, radioprotective 105 kDa protein; siRNA, small interfering RNA; EGFP, enhanced green fluorescent protein; CK, creatine kinase; CK-MB, MB isoenzyme of CK; LDH, lactate dehydrogenase; sham, control sham group; I/R, ischemic and reperfusion; Ad-R, Ad-RP105 group; Ad-R-siRNA, Ad-RP105-siRNA group; Ad-G-siRNA, Ad-EGFP-siRNA group.

results suggested that compared with the Ad-G-siRNA group, the expression levels of TLR2 and TLR4 were significantly increased in the RP105 knockdown group (Fig. 4A-C). However, both the expression levels of TLR 2 and TLR4 in the RP105 overexpression group were significantly decreased compared with the I/R group (Fig. 4A-C). Overexpression of RP105 decreased the interaction between MD2 and TLR2/4, while knockdown of RP105 increased the interaction of MD2 and TLR2/4 (Fig. 4C). Similarly, compared with control groups, after knockdown of RP105, the expression levels of inflammatory factors interleukin (IL-6) and tumor necrosis factor (TNF)- $\alpha$ were significantly increased, but they were decreased following overexpression of RP105 (Fig. 4D-F). The present results suggested that RP105 may negatively regulate the TLR2/4 signaling pathway in MIRI.

Silencing of RP105 increases myocardial apoptosis. To detect whether knockdown of RP105 was associated with apoptosis of myocardial cells, the expression levels of apoptosis-related markers were investigated. The present results suggested that 
A

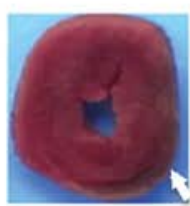

Sham

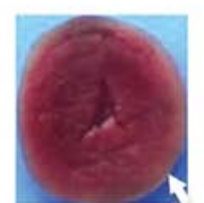

I/R

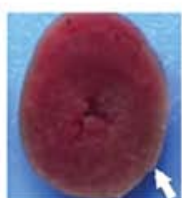

Ad-R

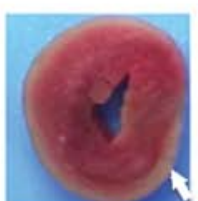

Ad-R-siRNA

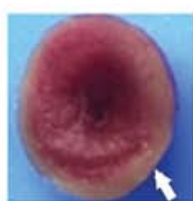

Ad-G-siRNA

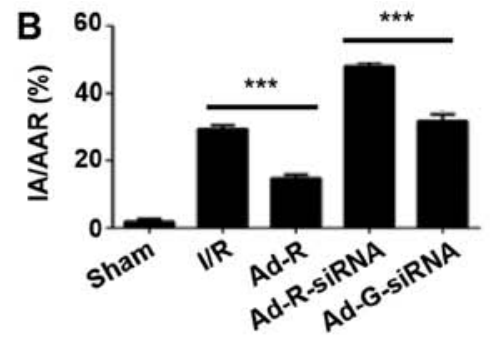

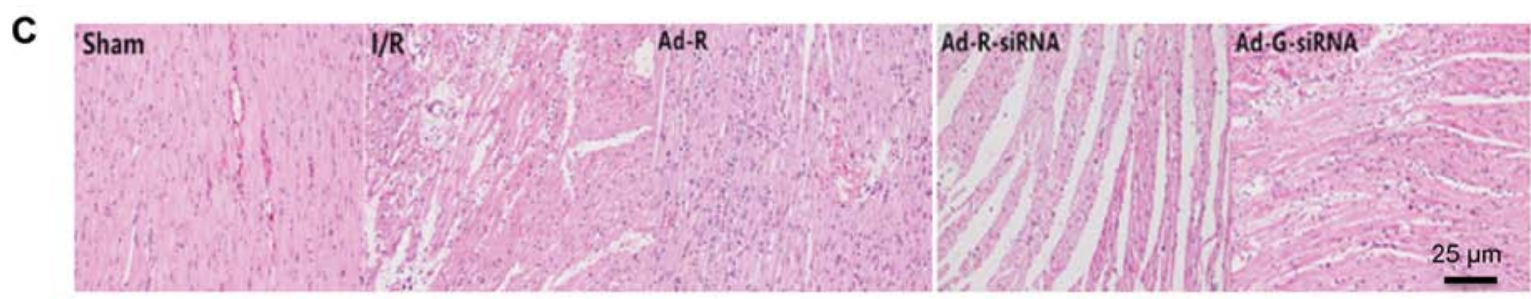

Figure 3. Silencing of RP105 increases myocardial infarction during MIRI. (A) Area of myocardial infarction in each group was imaged and analyzed using Image-Pro Plus 5. The injury areas were highlighted with white arrows. (B) Statistical analysis of the myocardial infarction of each group. (C) Hematoxylin and eosin staining of the myocardium tissue slices in each group. Scale bar, $25 \mu \mathrm{m}$. ${ }^{* * *} \mathrm{P}<0.001$. Ad, adenovirus; RP105, radioprotective $105 \mathrm{kDa}$ protein; siRNA, small interfering RNA; EGFP, enhanced green fluorescent protein; sham, control sham group; I/R, ischemic and reperfusion; Ad-R, Ad-RP105 group; Ad-R-siRNA, Ad-RP105-siRNA group; Ad-G-siRNA, Ad-EGFP-siRNA group; IA, infarct area; AAR, area at risk.
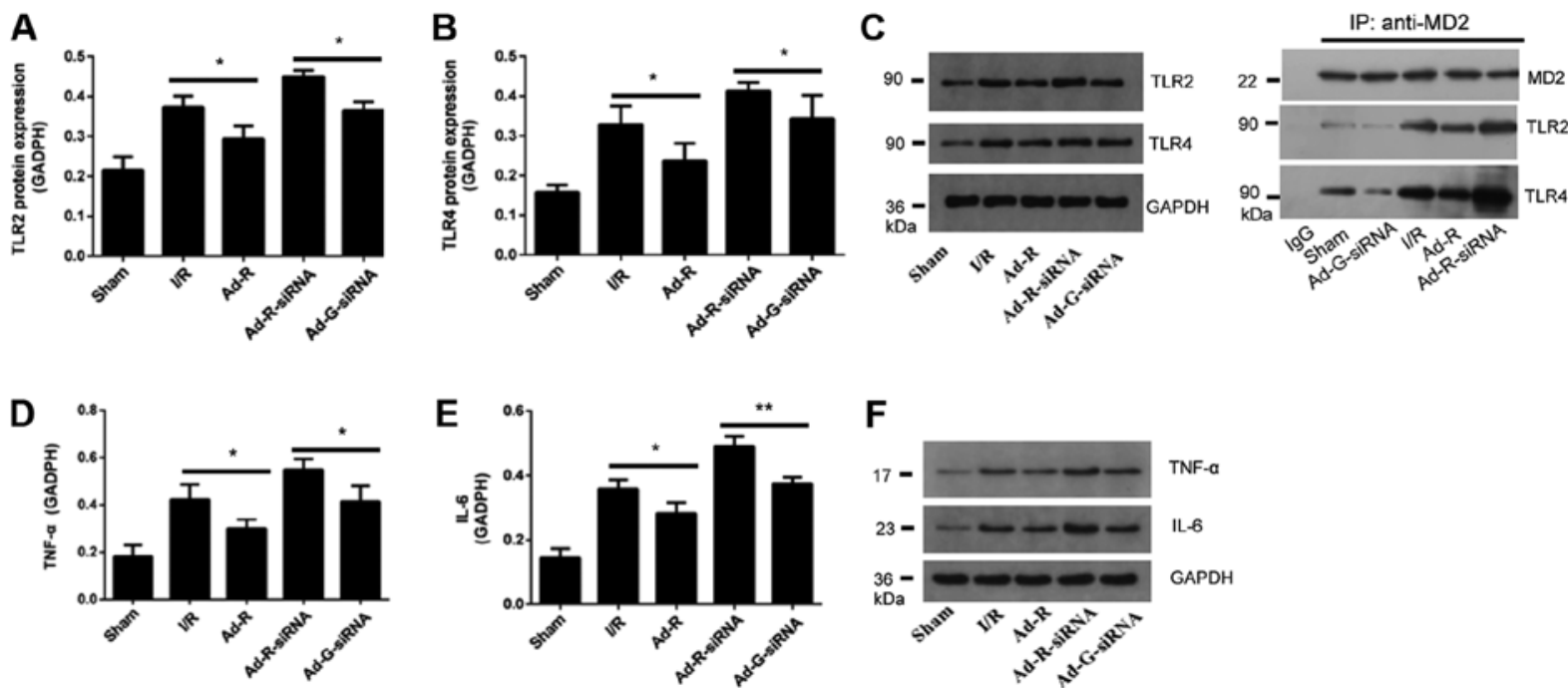

Figure 4. Knockdown of RP105 increases the expression levels of TLR2 and TLR4 in MIRI. Protein expression levels of serum (A) TLR2 and (B) TLR4 in each group. (C) Western blotting for the expression levels of TLR2 and TLR4 in each group. The interactions of MD2 with TLR2 and TLR4 following overexpression or knockdown of RP105 were investigated. Expression level of (D) TNF- $\alpha$ and (E) IL-6 in each group. (F) Western blotting bands of TNF- $\alpha$ and IL-6. ${ }^{*} \mathrm{P}<0.05,{ }^{* *} \mathrm{P}<0.01$. Ad, adenovirus; RP105, radioprotective $105 \mathrm{kDa}$ protein; siRNA, small interfering RNA; EGFP, enhanced green fluorescent protein; sham, control sham group; I/R, ischemic and reperfusion; Ad-R, Ad-RP105 group; Ad-R-siRNA, Ad-RP105-siRNA group; Ad-G-siRNA, Ad-EGFP-siRNA group; TLR2/4, Toll-like receptor 2/4; TNF- $\alpha$, tumor necrosis factor; IL-6, interleukin 6; MD2, myeloid differentiation protein 2; IP, immunoprecipitation.

the protein expression level of Bcl-2 in myocardial tissue with overexpressed RP105 was significantly higher compared with the I/R group, while knockdown of RP105 decreased the expression level of Bcl-2 (Fig. 5A and C). In addition, the protein expression level of cleaved caspase-3 in RP105 overexpressed group was significantly decreased compared with the control group (Fig. 5B and C). The expression level of cleaved caspase-3 with RP-105 knockdown was significantly increased.

Knockdown of RP105 may regulate the MyD88 and NF- $\kappa B$ signaling pathways. The expression levels of MyD88 and $\mathrm{NF}-\mathrm{\kappa B}$ in rat myocardium following myocardial ischemia for
$30 \mathrm{~min}$ and reperfusion for $3 \mathrm{~h}$ were investigated. The protein expression levels of inflammatory factors MyD88 and NF- $\mathrm{KB}$ were significantly increased after knockdown of RP-105 compared with the control group (Fig. 6A-C). The protein expression levels of MyD88 and NF- $\mathrm{KB}$ in the presence of RP-105 were significantly reduced compared with the control groups. There was no significant difference between the I/R group and the Ad-G-siRNA group (Fig. 6A-C).

\section{Discussion}

Previous studies have shown that the prevention and treatment of MIRI depends on the following features: i) Simply targeting 

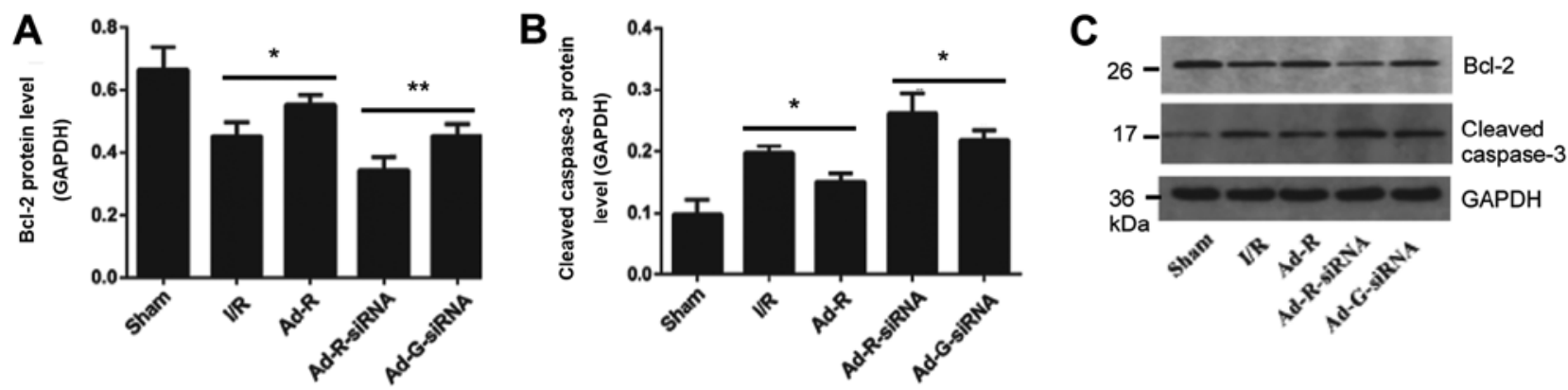

Figure 5. Silencing of RP105 increases myocardial apoptosis. Protein expression levels of serum (A) Bcl-2 and (B) cleaved caspase-3 in each group. (C) Western blotting bands of Bcl-2 and cleaved caspase-3. ${ }^{*} \mathrm{P}<0.05,{ }^{* * *} \mathrm{P}<0.01$. Ad, adenovirus; RP105, radioprotective 105 kDa protein; siRNA, small interfering RNA; EGFP, enhanced green fluorescent protein; sham, control sham group; I/R, ischemic and reperfusion; Ad-R, Ad-RP105 group; Ad-R-siRNA, Ad-RP105-siRNA group; Ad-G-siRNA, Ad-EGFP-siRNA group.
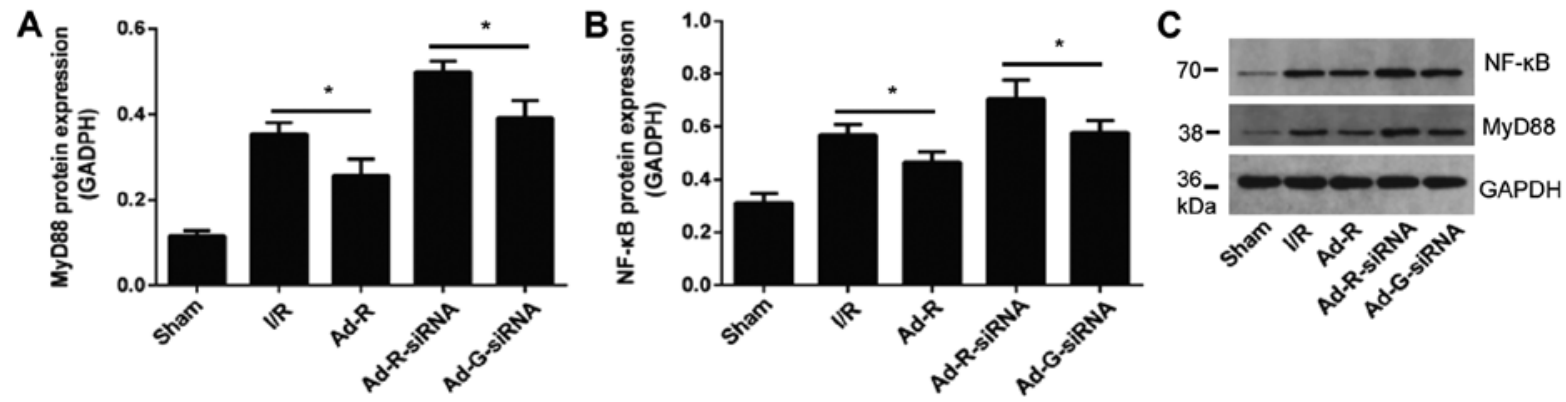

Figure 6. Knockdown of RP105 regulates the MyD88 signaling pathway. Protein expression levels of serum (A) MyD88 and (B) NF- $\mathrm{kB}$ in each group. (C) Western blotting bands of MyD88 and NF- $\mathrm{kB}$ in each group. ${ }^{*} \mathrm{P}<0.05$. Ad, adenovirus; RP105, radioprotective $105 \mathrm{kDa}$ protein; siRNA, small interfering RNA; EGFP, enhanced green fluorescent protein; sham, control sham group; I/R, ischemic and reperfusion; Ad-R, Ad-RP105 group; Ad-R-siRNA, Ad-RP105-siRNA group; Ad-G-siRNA, Ad-EGFP-siRNA group; MyD88, myeloid differentiation factor 88.

the protective gene or harmful gene; ii) interfering with the expression of a single gene to play a comprehensive role in multiple pathogenic processes; or iii) modulating the expression of target genes via non-coding RNAs $(27,28)$. Although these strategies provide novel ways to alleviate MIRI, the clinical effect is still unsatisfactory $(22,24,29-31)$. This may be due to the following reasons: i) MIRI results from the imbalance of both protective genes and harmful genes, and therefore unilateral intervention has limited impact; ii) both upstream and downstream pathways regulate MIRI, meaning targeting a single factor cannot fully control the pathological process; and iii) non-coding RNAs are involved in the progression of MIRI (32-34).

Previous studies have shown that serine/threonine kinase receptor-associated proteins regulated cell proliferation and apoptosis, and mediated the immune response to pathogens via the TLR2/4 signaling pathway (35-37). Our previous studies showed that RP105 plays a negative role in the TLR4 signaling pathway $(38,39)$. TLR4 recognizes, and is activated by, bacterial lipopolysaccharide (LPS) via the adaptor protein MD2, which induces the receptor heterodimer LPS/MD2/TLR4 on the cell membrane (40-42). The formation of the heterodimer initiates the intracellular TLR4/MyD88/NF- $\kappa B$ signaling cascade. The recruitment of MyD88 promotes the recruitment of secondary messengers and enzymes to form protein complexes, such as p38, c-Jun $\mathrm{N}$-terminal kinase and extracellular-signal-regulated kinases 1/2 (43). The following result is the activation of NF- $\mathrm{kB}$ and the transcription of target genes, including TNF- $\alpha$, IL-1 $\beta$ and IL-18 (25). Additionally, with the activation of TLR4, TRIF-related adaptor protein promotes conformational changes in TRIF, and recruits TNF receptor associated factor 3 (TRAF3) and TRAF6, eventually leading to the nuclear translocation of NF- $\mathrm{KB}$ and AP-1 (44). In the present study, silencing of RP-105 triggered apoptotic and inflammatory-related pathways in rats, suggesting a negative role for RP-105 in the inflammatory response. The present results suggested that RP105 may be utilized as an inhibitor of the TLR4 inflammatory signaling pathway to treat MIRI.

Numerous signaling pathways are involved in the remodeling of the cardiovasculature $(45,46)$. Vascular and inflammatory cells-derived matrix metalloproteinases and cysteine proteases play key roles in cardiovascular remodeling and atherosclerotic plaque growth in human and animal models (47-50). TLR2 has been found to bind more ligands than other members of the TLR family (51). An increase in TLR2 ligands significantly activates the PI3K/Akt pathway and protects myocardium from ischemic injury, which indicates the cardioprotective role of TLR2 in ischemic injury (52). RP105 is associated with the TLR2 signaling pathway in mediating inflammatory responses (53). A previous study showed that Staphylococcus aureus activates RP105 in macrophages to induce the accumulation of TLR2 (54). The increased TLR 2 by inflammatory cytokines via MyD88 leads to infection resistance in rats (54). After Mycobacterium tuberculosis infection, RP105 interacts with TLR2 and 
modulates the inflammatory response (55). TLR 2 forms a complex with TLR1 and TLR6, which identify bacterial lipoproteins by recruiting the TIR domain-containing adaptor protein and MyD88 (56). RP105/MD1 interacts with TLR2 to activate $\mathrm{NF}-\kappa \mathrm{B}$ and MAPK in macrophages, which promote the release of inflammatory factors (53). However, excessive inhibition of TLR2 may result in unfavorable remodeling in the cardiac tissue (57). Therefore, inflammation may be a double-edged sword, and a balance between regulating the infarct size and the healing of damaged myocardium needs to be investigated (58).

Acting as a homologue of TLR, RP105 promotes the response of TLR2 ligand receptor by forming a heterologous complex and negatively regulates TLR4 signaling in macrophages (53). RP105 is a possible factor in the immune response (53); however, whether RP105 interferes with TLR2/4 and affects the progression of MIRI is not fully known. RP105 was reported as a critical regulator of TLR4 to alleviate MIRI by regulating the activation of the TLR4/Myd88 or TLR4/TRIF/IRF3 signaling pathway $(17,38)$. Moreover, an equilibrium state of the RP105-TLR2/4 signaling pathway is maintained under normal cardiomyocytes, whereas MIRI causes the imbalance of the RP105-TLR2/4 signaling pathway (59). The present results suggested the involvement of RP105 in the myocardium, which indicated that TLR2 and TLR4 were key upstream regulators of ligand receptor signaling in modulating the process of MIRI.

The main limitation of this study is that the RP105 knockdown experiments were performed only in rats, rather than a higher primate species. However, using primate models is difficult for functional studies of RP105 in MIRI due to the lack of available drugs targeting RP105.

Various diseases caused by genetic mutations such as hypertrophic cardiomyopathy and restrictive cardiomyopathy still lack effective treatment strategies. The present results suggested RP105 targeted both TLR2 and TLR4, which indicated RP105 may be a promising candidate for the prevention and treatment of MIRI.

\section{Acknowledgements}

Not applicable.

\section{Funding}

The present study was supported by The National Natural Science Foundation of China (grant nos. 81402568, 81670333 and 81470387) and Hubei Province's Outstanding Medical Academic Leader Program and Technology Support Program of Hubei Province (grant no. 2015BKA340).

\section{Availability of data and materials}

The datasets used and/or analyzed during the current study are available from the corresponding author on reasonable request.

\section{Authors' contributions}

WLH and JuY designed the study. WLH performed the majority of experiments. JiY performed the H\&E staining and
CO-IP assays. $\mathrm{CH}$ analyzed the data. JuY wrote the manuscript. All authors contributed to the revision of the manuscript. All authors read and approved the final manuscript.

\section{Ethics approval and consent to participate}

The animal experiments were approved by the Animal Care and Use Department of China Three Gorges University.

\section{Patient consent for publication}

Not applicable.

\section{Competing interests}

The authors declare that they have no competing interests.

\section{References}

1. Dalen JE, Alpert JS, Goldberg RJ and Weinstein RS: The epidemic of the 20(th) century: Coronary heart disease. Am J Med 127: 807-812, 2014

2. Aggarwal B and Menon V: Recent advances in treatment of acute coronary syndromes. F1000Prime Rep 5: 56, 2013.

3. Alexander W: American academy of dermatology and american college of cardiology. P T 39: 370-374, 2014.

4. Levitsky S: Protecting the myocardial cell during coronary revascularization. The William W. L. Glenn lecture. Circulation 114 (Suppl 1): I339-I343, 2006.

5. Fang Y and Hu J: Toll-like receptor and its roles in myocardial ischemic/reperfusion injury. Med Sci Monit 17: RA100-RA109, 2011.

6. Akira S, Uematsu S and Takeuchi O: Pathogen recognition and innate immunity. Cell 124: 783-801, 2006.

7. Luo M, Yan D, Sun Q, Tao J, Xu L, Sun H and Zhao H: Ginsenoside $\mathrm{Rg} 1$ attenuates cardiomyocyte apoptosis and inflammation via the TLR4/NF-kB/NLRP3 pathway. J Cell Biochem: Nov 11, 2019 (Epub ahead of print).

8. Akbarshahi H, Axelsson JB, Said K, Malmström A, Fischer H and Andersson R: TLR4 dependent heparan sulphate-induced pancreatic inflammatory response is IRF3-mediated. J Transl Med 9: 219, 2011

9. Chen PG, Guan YJ, Zha GM, Jiao XQ, Zhu HS, Zhang CY, Wang YY and Li HP: Swine IRF3/IRF7 attenuates inflammatory responses through TLR4 signaling pathway. Oncotarget 8: 61958-61968, 2017.

10. Wang Y, Chen L, Tian Z, Shen X, Wang X, Wu H, Zou J and Liang J: CRISPR-Cas9 mediated gene knockout in human coronary artery endothelial cells reveals a pro-inflammatory role of TLR2. Cell Biol Int 42: 187-193, 2018.

11. Ohto U, Miyake $\mathrm{K}$ and Shimizu T: Crystal structures of mouse and human RP105/MD-1 complexes reveal unique dimer organization of the toll-like receptor family. J Mol Biol 413: 815-825, 2011.

12. Miyake K, Yamashita Y, Hitoshi Y, Takatsu K and Kimoto M: Murine B cell proliferation and protection from apoptosis with an antibody against a $105-\mathrm{kD}$ molecule: Unresponsiveness of X-linked immunodeficient B cells. J Exp Med 180: 1217-1224, 1994.

13. Selimovic D, Hassan M, Haikel Y and Hengge UR: Taxol-induced mitochondrial stress in melanoma cells is mediated by activation of c-Jun N-terminal kinase (JNK) and p38 pathways via uncoupling protein 2. Cell Signal 20: 311-322, 2008.

14. Karper JC, Ewing MM, de Vries MR, de Jager SC, Peters EA, de Boer HC, van Zonneveld AJ, Kuiper J, Huizinga EG, Brondijk TH, et al: TLR accessory molecule RP105 (CD180) is involved in post-interventional vascular remodeling and soluble RP105 modulates neointima formation. PLoS One 8: e67923, 2013.

15. Wezel A, van der Velden D, Maassen JM, Lagraauw HM, de Vries MR, Karper JC, Kuiper J, Bot I and Quax PH: RP105 deficiency attenuates early atherosclerosis via decreased monocyte influx in a CCR2 dependent manner. Atherosclerosis 238: 132-139, 2015. 
16. Yang H, Wang H, Ju Z, Ragab AA, Lundbäck P, Long W, Valdes-Ferrer SI, He M, Pribis JP, Li J, et al: MD-2 is required for disulfide HMGB1-dependent TLR4 signaling. J Exp Med 212: 5-14, 2015.

17. Li X, Yang J, Yang J, Dong W, Li S, Wu H and Li L: RP105 protects against myocardial ischemia-reperfusion injury via suppressing TLR4 signaling pathways in rat model. Exp Mol Pathol 100: 281-286, 2016.

18. Yang J, Yang C, Yang J, Ding J, Li X, Yu Q, Guo X, Fan Z and Wang H: RP105 alleviates myocardial ischemia reperfusion injury via inhibiting TLR4/TRIF signaling pathways. Int J Mol Med 41: 3287-3295, 2018.

19. Liu QS, Cheng ZW, Xiong JG, Cheng S, He XF and Li XC: Erythropoietin pretreatment exerts anti-inflammatory effects in hepatic ischemia/reperfusion-injured rats via suppression of the TLR2/NF-kappaB pathway. Transplant Proc 47: 283-289, 2015.

20. Pope MR and Fleming SD: TLR 2 modulates antibodies required for intestinal ischemia/reperfusion-induced damage and inflammation. J Immunol 194: 1190-1198, 2015.

21. Ulbrich F, Lerach T, Biermann J, Kaufmann KB, Lagreze WA, Buerkle H, Loop T and Goebel U: Argon mediates protection by interleukin-8 suppression via a TLR2/TLR4/STAT3/NF-kappaB pathway in a model of apoptosis in neuroblastoma cells in vitro and following ischemia-reperfusion injury in rat retina in vivo. J Neurochem 138: 859-873, 2016.

22. Yang J, Chen L, Yang J, Ding J, Li S, Wu H, Zhang J, Fan Z, Dong $\mathrm{W}$ and Li X: MicroRNA-22 targeting CBP protects against myocardial ischemia-reperfusion injury through anti-apoptosis in rats. Mol Biol Rep 41: 555-561, 2014.

23. Wang HB, Yang J, Ding JW, Chen LH, Li S, Liu XW, Yang CJ, Fan ZX and Yang J: RNAi-mediated down-regulation of CD47 protects against ischemia/reperfusion-induced myocardial damage via activation of eNOS in a rat model. Cell Physiol Biochem 40: 1163-1174, 2016.

24. Wang B, Zhong S, Zheng F, Zhang Y, Gao F, Chen Y, Lu B, Xu H and Shi G: N-n-butyl haloperidol iodide protects cardiomyocytes against hypoxia/reoxygenation injury by inhibiting autophagy. Oncotarget 6: 24709-24721, 2015.

25. Zhang X, Du Q, Yang Y, Wang J, Dou S, Liu C and Duan J: The protective effect of Luteolin on myocardial ischemia/reperfusion (I/R) injury through TLR4/NF-kappaB/NLRP3 inflammasome pathway. Biomed Pharmacother 91: 1042-1052, 2017.

26. Livak KJ and Schmittgen TD: Analysis of relative gene expression data using real-time quantitative PCR and the 2(-Delta Delta C(T)) method. Methods 25: 402-408, 2001.

27. Liu NB, Wu M, Chen C, Fujino M, Huang JS, Zhu P and Li XK: Novel molecular targets participating in myocardial ischemia-reperfusion injury and cardioprotection. Cardiol Res Pract 2019: 6935147, 2019.

28. Davidson SM, Ferdinandy P, Andreadou I, Bøtker HE, Heusch G, Ibáñez B, Ovize M, Schulz R, Yellon DM, Hausenloy DJ, et al: Multitarget strategies to reduce myocardial ischemia/reperfusion injury: JACC review topic of the week. J Am Coll Cardiol 73: 89-99, 2019.

29. Quiat D and Olson EN: MicroRNAs in cardiovascular disease: From pathogenesis to prevention and treatment. J Clin Invest 123: $11-18,2013$.

30. Wang JX, Zhang XJ, Li Q, Wang K, Wang Y, Jiao JQ, Feng C, Teng S, Zhou LY, Gong Y, et al: MicroRNA-103/107 regulate programmed necrosis and myocardial ischemia/reperfusion injury through targeting FADD. Circ Res 117: 352-363, 2015.

31. Yang CJ, Yang J, Yang J and Fan ZX: Radioprotective 105kDa protein (RP105): Is a critical therapeutic target for alleviating ischemia reperfusion induced myocardial damage via TLR4 signaling pathway. Int J Cardiol 222: 1069-1070, 2016.

32. Eltzschig HK and Eckle T: Ischemia and reperfusion-from mechanism to translation. Nat Med 17: 1391-1401, 2011.

33. Joshi S, Wei J and Bishopric NH: A cardiac myocyte-restricted Lin28/let-7 regulatory axis promotes hypoxia-mediated apoptosis by inducing the AKT signaling suppressor PIK3IP1. Biochim Biophys Acta 1862: 240-251, 2016.

34. Sun Y, Ye L, Jiang C, Jiang J, Hong H and Qiu L: Over-expression of HSPA12B protects mice against myocardium ischemic/ reperfusion injury through a PPARgamma-dependent PI3K/Akt/eNOS pathway. Am J Transl Res 7: 2724-2737, 2015.

35. Huh HD, Ra EA, Lee TA, Kang S, Park A, Lee E, Choi JL, Jang E, Lee JE, Lee S and Park B: STRAP acts as a scaffolding protein in controlling the TLR2/4 signaling pathway. Sci Rep 6: 38849, 2016
36. Takeda $\mathrm{K}$ and Akira S: TLR signaling pathways. Semin Immunol 16: 3-9, 2004.

37. Dunne A, Carpenter S, Brikos C, Gray P, Strelow A, Wesche H, Morrice N and O'Neill LA: IRAK1 and IRAK4 promote phosphorylation, ubiquitination, and degradation of MyD88 adaptor-like (Mal). J Biol Chem 291: 24802, 2016.

38. Guo X, Jiang H, Yang J, Chen J, Yang J, Ding JW, Li S, Wu H and Ding HS: Radioprotective $105 \mathrm{kDa}$ protein attenuates ischemia/reperfusion-induced myocardial apoptosis and autophagy by inhibiting the activation of the TLR4/NF-kappaB signaling pathway in rats. Int J Mol Med 38: 885-893, 2016.

39. Yang J, Guo X, Yang J, Ding JW, Li S, Yang R, Fan ZX and Yang CJ: RP105 protects against apoptosis in ischemia/reperfusion-induced myocardial damage in rats by suppressing TLR4-mediated signaling pathways. Cell Physiol Biochem 36: 2137-2148, 2015.

40. Nagai Y, Akashi S, Nagafuku M, Ogata M, Iwakura Y, Akira S, Kitamura T, Kosugi A, Kimoto M and Miyake K: Essential role of MD-2 in LPS responsiveness and TLR4 distribution. Nat Immunol 3: 667-672, 2002.

41. Brandl K, Glück T, Hartmann P, Salzberger B and Falk W. A designed TLR4/MD-2 complex to capture LPS. J Endotoxin Res 11: 197-206, 2005.

42. Roh E, Lee HS, Kwak JA, Hong JT, Nam SY, Jung SH, Lee JY, Kim ND, Han SB and Kim Y: MD-2 as the target of nonlipid chalcone in the inhibition of endotoxin LPS-induced TLR4 activity. J Infect Dis 203: 1012-1020, 2011.

43. Lee SM, Hutchinson M and Saint DA: The role of Toll-like receptor 4 (TLR4) in cardiac ischaemic-reperfusion injury, cardioprotection and preconditioning. Clin Exp Pharmacol Physiol 43: 864-871, 2016.

44. Piao W, Ru LW, Piepenbrink KH, Sundberg EJ, Vogel SN and Toshchakov VY: Recruitment of TLR adapter TRIF to TLR4 signaling complex is mediated by the second helical region of TRIF TIR domain. Proc Natl Acad Sci USA 110: 19036-19041, 2013.

45. Ayme-Dietrich E, Aubertin-Kirch G, Maroteaux L and Monassier L: Cardiovascular remodeling and the peripheral serotonergic system. Arch Cardiovasc Dis 110: 51-59, 2017.

46. Ayme-Dietrich E, Marzak H, Lawson R, Mokni W, Wendling O, Combe R, Becker J, El Fertak L, Champy MF, Matz R, et al: Contribution of serotonin to cardiac remodeling associated with hypertensive diastolic ventricular dysfunction in rats. J Hypertens 33: 2310-2321, 2015.

47. Lei Y, Yang G, Hu L, Piao L, Inoue A, Jiang H, Sasaki T, Zhao G, Yisireyili M, Yu C, et al: Increased dipeptidyl peptidase-4 accelerates diet-related vascular aging and atherosclerosis in ApoE-deficient mice under chronic stress. Int J Cardiol 243: 413-420, 2017.

48. Yang G, Lei Y, Inoue A, Piao L, Hu L, Jiang H, Sasaki T, Wu H, $\mathrm{Xu} \mathrm{W}$, Yu C, et al: Exenatide mitigated diet-induced vascular aging and atherosclerotic plaque growth in ApoE-deficient mice under chronic stress. Atherosclerosis 264: 1-10, 2017.

49. Cheng XW, Huang Z, Kuzuya M, Okumura K and Murohara T: Cysteine protease cathepsins in atherosclerosis-based vascular disease and its complications. Hypertension 58: 978-986, 2011

50. Cheng XW, Shi GP, Kuzuya M, Sasaki T, Okumura K and Murohara T: Role for cysteine protease cathepsins in heart disease: Focus on biology and mechanisms with clinical implication. Circulation 125: 1551-1562, 2012.

51. Selmi C: Autoimmunity in 2016. Clin Rev Allergy Immunol 53: 126-139, 2017.

52. Ha T, Hu Y, Liu L, Lu C, McMullen JR, Kelley J, Kao RL, Williams DL, Gao $X$ and Li C: TLR2 ligands induce cardioprotection against ischaemia/reperfusion injury through a PI3K/Akt-dependent mechanism. Cardiovasc Res 87: 694-703, 2010.

53. Liu B, Zhang N, Liu Z, Fu Y, Feng S, Wang S, Cao Y,Li D, Liang D, $\mathrm{Li} \mathrm{F}$, et al: RP105 involved in activation of mouse macrophages via TLR2 and TLR4 signaling. Mol Cell Biochem 378: 183-193, 2013.

54. Liu B, Fu Y, Feng S, Zhang X, Liu Z, Cao Y, Li D, Liang D, Li F, Zhang N and Yang Z: Involvement of RP105 and toll-like receptors in the activation of mouse peritoneal macrophages by Staphylococcus aureus. Scand J Immunol 78: 8-16, 2013.

55. Blumenthal A, Kobayashi T, Pierini LM, Banaei N, Ernst JD, Miyake K and Ehrt S: RP105 facilitates macrophage activation by Mycobacterium tuberculosis lipoproteins. Cell Host Microbe 5: 35-46, 2009. 
56. Frazao JB, Errante PR and Condino-Neto A: Toll-like receptors pathway disturbances are associated with increased susceptibility to infections in humans. Arch Immunol Ther Exp (Warsz) 61: 427-443, 2013.

57. Mersmann J, Habeck K, Latsch K, Zimmermann R, Jacoby C, Fischer JW, Hartmann C, Schrader J, Kirschning CJ and Zacharowski K: Left ventricular dilation in toll-like receptor 2 deficient mice after myocardial ischemia/reperfusion through defective scar formation. Basic Res Cardiol 106: 89-98, 2011

58. Lepper PM and Bals R: On the edge: Targeting Toll-like receptor 2 in ischemia/reperfusion injury. Circ Cardiovasc Interv 5: 146-149, 2012.
59. Divanovic S, Trompette A, Petiniot LK, Allen JL, Flick LM, Belkaid Y, Madan R, Haky JJ and Karp CL: Regulation of TLR4 signaling and the host interface with pathogens and danger: The role of RP105. J Leukoc Biol 82: 265-271, 2007.

cc) (i) $(-)$ This work is licensed under a Creative Commons EY NO ND Attribution-NonCommercial-NoDerivatives 4.0 International (CC BY-NC-ND 4.0) License. 